\title{
Collecting duct carcinoma of the kidney: A case report
}

\author{
YU HU $^{1 *}$, HONGLAN ZHOU $^{2 *}$, GANG WANG $^{2}$, ZHIMING SONG $^{3}$, CHENGWU ZHAO $^{3}$ and YUANTAO WANG ${ }^{2}$ \\ ${ }^{1}$ Department of Pathology, Sino-Japanese Friendship Hospital, Jilin University, Changchun, Jilin 130033; \\ Departments of ${ }^{2}$ Urology and ${ }^{3}$ Arthroscopy, First Hospital of Jilin University, Changchun, Jilin 130021, P.R. China
}

Received July 9, 2014; Accepted March 13, 2015

DOI: 10.3892/ol.2015.3085

\begin{abstract}
Collecting duct carcinoma (CDC) is a rare type of renal tumor, arising from the distal collecting ducts. The prognosis of this disease is extremely poor due to its rapid progression with widespread metastases. The present study reported a case of CDC involving the right renal region of a 62-year-old female patient, presented with right-flank pain that had persisted for one month. A computed tomography scan demonstrated multiple hypoattenuating quasicircular lesions, $0.5-4.3 \mathrm{~cm}$ in size, in the upper pole of the right kidney. Following the diagnosis of a right renal tumor, laparoscopic radical resection of the right kidney was performed. Pathological examination demonstrated that the tumor cells were arranged in a glandular or papillary pattern, and marked cytological atypia was observed. Immunohistochemical staining revealed that the tumor cells were positive for epithelial membrane antigen and cytokeratin (CK)7, while they reacted focally with vimentin. However, the tumor cells were negative for CK20, CD10, uroplakin III and p63. Based on these findings, the patient was diagnosed with CDC. In conclusion, immunohistochemical analysis is critical in establishing an accurate diagnosis of CDC and distinguishing this tumor from other subtypes of RCC.
\end{abstract}

\section{Introduction}

Collecting duct carcinoma (CDC) is a rare subtype of renal epithelial neoplasm, accounting for $<2 \%$ of all the renal cell carcinoma (RCC) cases (1). This aggressive malignancy is considered to be derived from the collecting duct of the kidney and has a poor prognosis in the majority of patients (2-5) with a median survival time of only 22 months following nephrectomy (6). Despite the histological and immunohistochemical features of this disease, distinguishing CDC from pelvic urothelial carcinoma and high-grade papillary RCC is difficult,

Correspondence to: Dr Yuantao Wang, Department of Urology, First Hospital of Jilin University, 71 Xinmin Street, Changchun, Jilin 130021, P.R. China

E-mail: wangyuantaojdyy@163.com

*Contributed equally

Key words: kidney, collecting duct carcinoma, neoplasm, diagnosis mainly due to the varying features of CDC (7). The tumor is usually identified in or proximal to the renal pelvis and appears gray or white without extensive necrosis or hemorrhage (8). Various treatments have been reported in the literature, including immunotherapy, radiation therapy, chemotherapy $(5,9)$ and radical excision (3). In order to improve the understanding on the biological behavior of CDC, the present study reported the case of a 62-year-old female patient with typical pathological features of CDC. In addition, the clinical, pathological and immunohistochemical aspects of the disease were reviewed. Written informed consent was obtained from the patient.

\section{Case report}

In August 2013, a 62-year-old female was admitted to the First Hospital of Jilin University (Changchun, China) for evaluation of right-flank pain that had persisted for one month. The patient did not experience gross hematuria or dysuria. A physical examination was unremarkable, with the exception of mild percussion pain in the right kidney area. Blood examinations revealed an elevated erythrocyte sedimentation rate $[41 \mathrm{ml} / \mathrm{h}$; normal range, $4-30 \mathrm{ml} / \mathrm{h}$ (10)]. An abdominal ultrasonography scan demonstrated a solid, hypoechoic and relatively well-demarcated tumor, approximately $6.9 \times 5.6 \mathrm{~cm}$ in size, occupying the right kidney. Contrast-enhanced computed tomography examination of the abdomen and pelvis revealed multiple hypoattenuating quasicircular lesions, $0.5-4.3 \mathrm{~cm}$ in size, in the upper pole of the right kidney. The mass presented minimal contrast enhancement following administration of Omnipaque contrast agent $[100 \mathrm{ml}$; GE Healthcare (Shanghai) Co., Ltd., Shanghai, China] (Fig. 1). No evidence of renal vein invasion, lymph node or distant metastasis was observed.

Based on the clinical and imaging findings, a laparoscopic radical resection of the right kidney was performed in order to excise the tumor. Macroscopic examination of the resected tissue revealed a $4 \times 4 \times 3.5 \mathrm{~cm}$ tan-yellow, well-circumscribed, soft tumor, which was occupying almost the entire upper pole of the kidney. The tumor had invaded the renal pelvis and renal sinus fat, while a large area of necrosis and a satellite lesion were observed in the mass. In addition, a microscopic examination was performed and the characteristic features observed included a tubulopapillary growth pattern, significant pleomorphism of the neoplastic cells and local sarcomatoid changes (Fig. 2A). Thus, the tumor was classified as nuclear grade III using the Fuhrman grading system (11). Immunohistochemical analysis revealed that the tumor cells were strongly positive for 

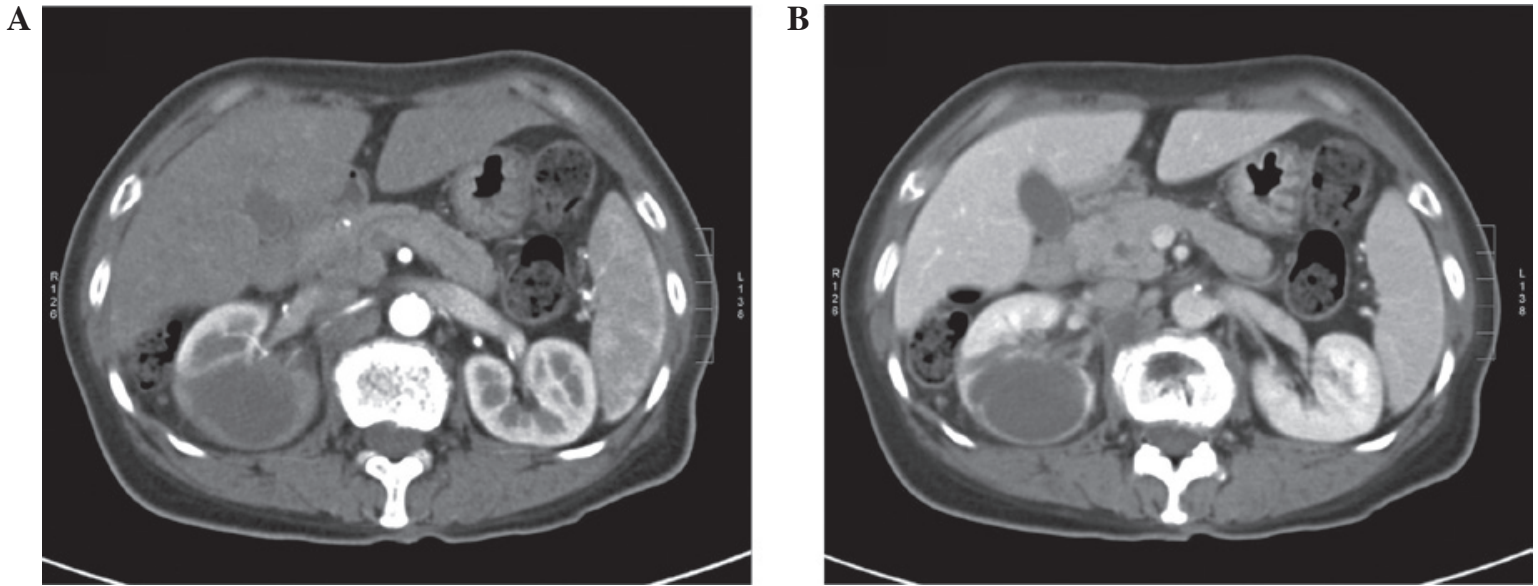

Figure 1. Computed tomography scans demonstrating multiple hypoattenuating quasicircular lesions invading the right renal area, with minimal contrast enhancement in the (A) arterial phase and (B) venous phase.
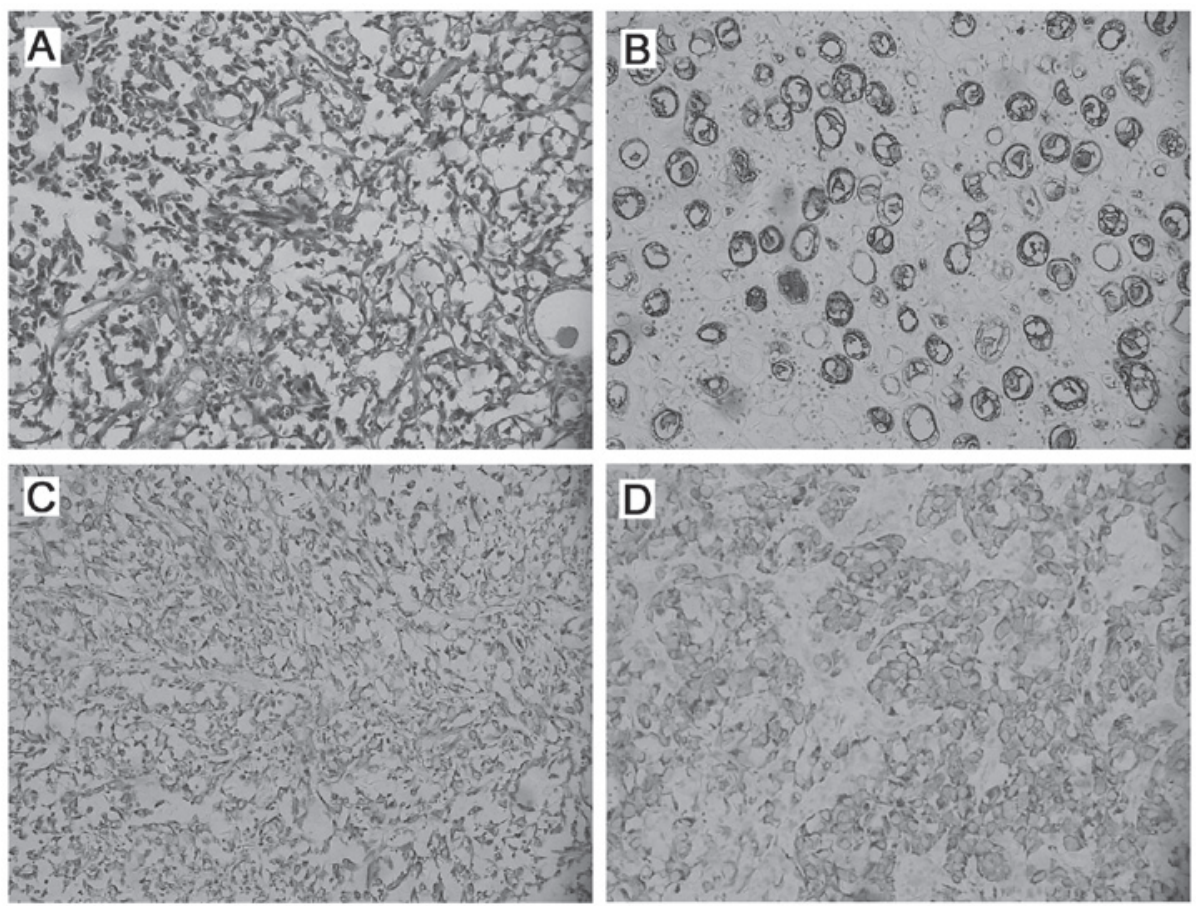

Figure 2. Pathological changes of collecting duct carcinoma. (A) Tubulopapillary growth pattern, significant pleomorphism of the neoplastic cells and local sarcomatoid changes were present throughout the tumor (hemoxylin and eosin stain; magnification, x200). The tumor cells were positive for (B) epithelial membrane antigen, (C) vimentin and (D) cytokeratin 7 (immunohistochemical staining, EnVision two-step technique; magnification, x200).

epithelial membrane antigen (EMA; Fig. 2B) and cytokeratin (CK)7 (Fig. 2D). The tumor cells also reacted focally with vimentin (Fig. 2C); however, they were negative for CK20, $\mathrm{CD} 10$, uroplakin III and p63. Based on the histopathological and immunohistochemical findings, a diagnosis of CDC was established. The patient was discharged eight days after surgery and no further treatments were administered. A CT scan performed 10 months after surgery revealed no recurrence or metastasis.

\section{Discussion}

$\mathrm{CDC}$ is a rare pathologic type of $\mathrm{RCC}$, with a tendency towards early dissemination and high mortality rates $(12,13)$. Although $\mathrm{CDC}$ is a rare tumor, its clinical presentation is nonspecific and may include symptoms of gross hematuria, backaches, weight loss and a local mass. In addition, the incidence of this tumor is higher in male adults aged between 41 and 71 years, with a 2:1 male to female ratio (14). At the time of diagnosis, the tumor is typically large, having a medullary origin and presenting with an infiltrative lesion. The majority of CDC tumors have been found to demonstrate focal cortical extension, while perirenal invasion was also common in large tumors (15). Since these tumors do not exhibit specific imaging features, a microscopic examination and immunohistochemical staining are required for the diagnosis of CDC (1). Microscopically, the common features include a tubulopapillary architecture, atypical hyperplastic changes, clear cytoplasm, evident stromal reaction with fiber hyperplasia and detached single cells with a 
hobnail surface (16). In the present case, the results of the microscopic examination revealed certain characteristic features of CDC, including a tubulopapillary growth pattern, significant pleomorphism of the neoplastic cells and local sarcomatoid changes. Positive immunohistochemical staining for CK19, CK7, 34ßE12 and vimentin has been previously reported to support the diagnosis of CDC (17). In addition, a previous study demonstrated that the CDC cells also express EMA, peanut lectin agglutinin and Ulex europaeus agglutinin 1 (18). In the present study, immunohistochemical analysis demonstrated that the tumor cells were strongly positive for EMA and CK7, while they reacted focally with vimentin. Therefore, the patient was diagnosed with CDC.

Regarding the treatment modality, surgery is performed in the majority of patients as a primary treatment $(13,19)$. In addition, a previous study demonstrated that combined chemotherapy with gemcitabine or carboplatin may be a promising treatment strategy for CDC patients, particularly those with advanced stage disease (20). However, radical nephrectomy or chemotherapy have not been found to effectively control the progressive form of this disease, due to the high rates of local recurrence and distant metastases (21). A previous study revealed that less than one third of patients survived for $>2$ years (15). In the present study, laparoscopic radical resection of the kidney was performed without chemotherapy or immunotherapy. No recurrence or metastasis was observed 10 months after surgery; however, further follow-up is required.

In conclusion, $\mathrm{CDC}$ is a rare, aggressive renal tumor that is frequently associated with nodal and visceral metastases at presentation. Since patients with CDC often present a poor prognosis, the early detection and diagnosis of this disease are vital. Histochemical and immunohistochemical analyses may provide adequate and reliable data in order to distinguish this tumor from other subtypes of RCC, resulting in the establishment of disease-specific treatment strategies.

\section{References}

1. Auguet T, Molina JC, Lorenzo A, Vila J, Sirvent JJ and Richart C: Synchronus renal cell carcinoma and Bellini duct carcinoma: a case report on a rare coincidence. World J Urol 18: 449-451, 2000.

2. Rumpelt HJ, Störkel S, Moll R, Schärfe T and Thoenes W: Bellini duct carcinoma: further evidence for this rare variant of renal cell carcinoma. Histopathology 18: 115-122, 1991.

3. Chao D, Zisman A, Pantuck AJ, Gitlitz BJ, Freedland SJ, Said JW, et al: Collecting duct renal cell carcinoma: clinical study of a rare tumor. J Urol 167: 71-74, 2002.
4. Karakiewicz PI, Trinh QD, Rioux-Leclercq N, de la Taille A, Novara G, Tostain J, et al: Collecting duct renal cell carcinoma: a matched analysis of 41 cases. Eur Urol 52: 1140-1145, 2007.

5. Tokuda N, Naito S, Matsuzaki O, Nagashima Y, Ozono S, Igarashi $\mathrm{T}$ and Japanese Society of Renal Cancer: Collecting duct (Bellini duct) renal cell carcinoma: a nationwide survey in Japan. J Urol 176: 40-43, 2006.

6. Dimopoulos MA, Logothetis CJ, Markowitz A, Sella A, Amato R and Ro J: Collecting duct carcinoma of the kidney. Br J Urol 71: 388-391, 1993.

7. Kafé H, Verbavatz JM, Cochand-Priollet B, Castagnet P and Vieillefond A: Collecting duct carcinoma: an entity to be redefined? Virchows Arch 445: 637-640, 2004

8. Gürocak S, Sözen S, Akyürek N, Uluoğlu O and Alkibay T: Cortically located collecting duct carcinoma. Urology 65: 1226, 2005.

9. Milowsky MI, Rosmarin A, Tickoo SK, Papanicolaou N and Nanus DM: Active chemotherapy for collecting duct carcinoma of the kidney: a case report and review of the literature. Cancer 94: 111-116, 2002.

10. Stojan G, Fang H, Magder L and Petri M: Erythrocyte sedimentation rate is a predictor of renal and overall SLE disease activity. Lupus 22: 827-834, 2013.

11. Ficarra V, Novara G and Martignoni G: The use of simplified versions of the Fuhrman nuclear grading system in clinical practice requires the agreement of a multidisciplinary panel of experts. Eur Urol 56: 782-784; discussion, 784-785, 2009.

12. Sironi M, Delpiano C, Claren R and Spinelli M: New cytological findings on fine-needle aspiration of renal collecting duct carcinoma. Diagn Cytopathol 29: 239-240, 2003.

13. Husillos A, Herranz-Amo F, Subirá D, Lledó E, Molina-Escudero R and Hernández-Fernández C: Collecting duct renal cell carcinoma. Actas Urol Esp 35: 368-371, 2011 (In Spanish).

14. Matz LR, Latham BI, Fabian VA and Vivian JB: Collecting duct carcinoma of the kidney: a report of three cases and review of the literature. Pathology 29: 354-359, 1997.

15. Pickhardt PJ: Collecting duct carcinoma arising in a solitary kidney: imaging findings. Clin Imaging 23: 115-118, 1999.

16. Kennedy SM, Merino MJ, Linehan WM, Roberts JR, Robertson CN and Neumann RD: Collecting duct carcinoma of the kidney. Hum Pathol 21: 449-456, 1990.

17. Molinié V, Balaton A, Rotman S, Mansouri D, De Pinieux I, Homsi $\mathrm{T}$ and Guillou L: Alpha-methyl CoA racemase expression in renal cell carcinomas. Hum Pathol 37: 698-703, 2006.

18. Li M, Vuolo MA, Weidenheim KM and Minsky LS: Collecting-duct carcinoma of the kidney with prominent signet ring cell features. Mod Pathol 14: 623-628, 2001.

19. Yoon SK, Nam KJ, Rha SH, et al: Collecting duct carcinoma of the kidney: CT and pathologic correlation. Eur J Radiol 57: 453-460, 2006.

20. Gollob JA, Upton MP, DeWolf WC and Atkins MB: Long-term remission in a patient with metastatic collecting duct carcinoma treated with taxol/carboplatin and surgery. Urology 58: 1058, 2001.

21. Kuroda N, Toi M, Hiroi M and Enzan H: Review of collecting duct carcinoma with focus on clinical and pathobiological aspects. Histol Histopathol 17: 1329-1334, 2002. 